\title{
Prevalence of nasal polyps in Northern Portugal: a cadaver endoscopic study*
}

\author{
Rui Cerejeira1,2, Rafaela Veloso-Teles ${ }^{3}$, Nuno Lousan' , Carla Pinto Moura² \\ ' Department of Otolaryngology, Tâmega e Sousa Hospital Center, Portugal \\ 2 Faculty of Medicine, University of Porto, Portugal \\ ${ }^{3}$ Department of Otolaryngology, Alto Ave Hospital Center, Portugal
}

Rhinology 52: 386-389, 2014

DOl:10.4193/Rhino14.016

*Received for publication:

January 26, 2014

Accepted: February 28, 2014

\begin{abstract}
Background: Epidemiological studies on chronic rhinosinusitis with nasal polyps are scarce and mostly based on questionnaires. Data obtained with such approaches can be unreliable, thus endoscopy is a prerequisite for an accurate estimate of the prevalence of nasal polyps. The objective of this study was to establish the frequency of nasal polyps in Northern Portugal, using nasal endoscopy in cadavers from a District Hospital.
\end{abstract}

Methods: The cadaver specimens deposited in the mortuary room of the hospital, every early morning on week days, from December 2012 to August 2013, were submitted to a systematic endoscopic examination of both nasal cavities, using a $25^{\circ}, 2.7 \mathrm{~mm}$ rigid endoscope from $\mathrm{R}$. Wolf ${ }^{\oplus}$. A review of the medical record of the cadavers was done, to search for cause of death, co-morbidities and past ENT history.

Results: A group of 200 consecutive caucasian cadaver specimens were analyzed, 83 women and 117 men, with a mean age of death of $77.23 \pm 12.29$ years (range 34-97). The prevalence of nasal polyps was 5.5\% (95\% confidence interval, 2.34-8.66). No statistically significant association between the studied clinical variables (sex, allergic rhinitis, lower respiratory diseases and smoking) and the presence of nasal polyps was identified.

Conclusion: This study provides the first endoscopic based epidemiological data on nasal polyps in Portugal, showing a prevalence for old age group in accordance with previous studies in Europe.

Key words: sinusitis, nasal cavity, respiratory tract diseases

\section{Introduction}

Epidemiological studies on chronic rhinosinusitis (CRS) with nasal polyps (NP) are scarce and mostly based on questionnaires. The data obtained with such approach can be unreliable as not all patients that claim to have NP have polyps on nasal endoscopy ${ }^{(1)}$ and asymptomatic polyps will be missing. According to the EPOS 2012 expert panel, endoscopy is, therefore, a prerequisite for an accurate estimate of the prevalence of NP (2).

Some population-based studies have estimated the prevalence of NP using endoscopy, with values ranging from 0.5 (Korea) to $2.7 \%$ (Sweden) $^{(1,3)}$.

A Danish team of investigators did some work in cadaver specimens, using anterior rhinoscopy, and found a prevalence of nasal polyps of $2 \%{ }^{(4-6)}$. The frequency of nasal polyps in 100 autopsies was, however, much higher, reaching 35\% of patients, a number considered by the authors as surprisingly high ${ }^{(7)}$. The objective of this study was to establish the frequency of 
nasal polyps in Northern Portugal, using nasal endoscopy in cadavers.

\section{Materials and methods}

The present study was approved by the Ethical Committee of the "Tâmega e Sousa Hospital Center". The target population of this Hospital comprises more than 500,000 inhabitants, situated in the "Vale do Sousa" and "Baixo Tâmega" regions, in Oporto district, Northern Portugal.

The material comprises a group of 200 cadaver specimens consecutively deposited in the mortuary room of the hospital, every early morning in week days, from December 2012 to August 2013. A systematic endoscopic examination of both nasal cavities was performed, using a $25^{\circ}, 2.7 \mathrm{~mm}$ rigid endoscope from R. Wolf ${ }^{\bullet}$; a suction system was used on an as-needed basis. A review of the medical record of the cadavers was done to search for cause of death, co-morbidities and past ENT history.

\section{Statistical analyses}

Data collected in the assessment was processed by statistical software IBM ${ }^{\circledR}$ SPSS $^{\circledR}$ Statistics, version 21, 2012.

Descriptive statistics of demographic and clinical data of the sample were calculated (sex, age at time of death, cause of death, morbidities, presence of nasal polyps). Fisher's exact test was used to determine the two-tailed statistical significance of differences between proportions in $2 \times 2$ tables. A p-value of less than 0.05 was considered significant.

\section{Results}

The sample consisted of 200 caucasian cadaver specimens, 83 women and 117 men. Mean age of death was 77.23 years, as shown in Table 1. Cause of death is depicted in Table 2, with no cases related to naso-sinusal pathology.

Polyps were identified in 11 cadavers (prevalence $=5.5 \%$; 95\% confidence interval, 2.34-8.66), 6 men and 5 women, and were characterized as shown in Table 3 . All cases were bilateral, with polyps emerging in the middle meatus. Mean age of death for this group was $75.36 \pm 9.146$ years (range 64-89 yr).

Just one patient with nasal polyps (9.1\%) had history of allergic rhinitis, comparing with 32 cadavers (16.9\%) with history of allergic rhinitis without nasal polyps. Chronic lower respiratory diseases ( 10 cases with asthma, 26 cases of chronic obstructive pulmonary disease, and one case of pulmonary fibrosis) affected 37 patients without polyps (19.6\%), but no history of lower respiratory disease was found in the group of patients with nasal polyps. Only one patient (9.1\%) with NP was a smoker, comparing with 38 (20.1\%) without polyps. Moreover, none of the patients with nasal polyps had a previous record of ENT observation.
Table 1. Age of death

\begin{tabular}{|ccccc|}
\hline & Mean & N & SD & Range \\
\hline Female & 81.27 & 83 & 9.116 & $36-97$ \\
\hline Male & 74.37 & 117 & 13.435 & $34-97$ \\
\hline Total & 77.23 & 200 & 12.291 & $34-97$ \\
\hline
\end{tabular}

$\mathrm{N}=$ number of specimens; $\mathrm{SD}=$ Standard Deviation

Table 2. Cause of death.

\begin{tabular}{|cc|}
\hline Cause of death & $\mathbf{N}(\%)$ \\
\hline Infectious & $83(41.5)$ \\
\hline Cardiovascular & $49(24.5)$ \\
\hline Neoplastic & $23(11.5)$ \\
\hline Traumatic & $5(2.5)$ \\
\hline Metabolic & $15(7.5)$ \\
\hline Other & $12(6)$ \\
\hline Unknown & $13(6.5)$ \\
\hline
\end{tabular}

$\mathrm{N}=$ number of specimens

Table 3. Characterization of nasal polyps identified in cadavers.

\begin{tabular}{|ccc|}
\hline Grade & $\mathbf{N}$ & $\%$ \\
\hline 0 (no polyps) & 189 & 94.5 \\
\hline 1 & 1 & 0.5 \\
\hline 2 & 7 & 3.5 \\
\hline 3 & 3 & 1.5 \\
\hline Total & 200 & 100 \\
\hline
\end{tabular}

$\mathrm{N}=$ number of specimens; Grading according to Lund ${ }^{(8)}$.

Table 4. Association between demographic and clinical variables and presence of Nasal Polyps: significance values $(n=200)$.

\begin{tabular}{|cc|}
\hline & $\begin{array}{c}\text { p value } \\
\text { Sex }\end{array}$ \\
\hline (Fisher's Exact Test, 2-sided)
\end{tabular}


As depicted in Table 4, none of the demographic and clinical variables were significantly related with the presence of nasal polyps ( $p>0.05)$.

\section{Discussion}

Chronic rhinosinusitis, with or without nasal polyps, constitutes an important health problem, with an estimated prevalence of $10.9 \%$ in Europe ${ }^{(9)}$. It has a significant impact in quality of life, interfering in personal, professional and social functioning. Despite all advances in the management of CRS, there is still little accurate information of its prevalence and incidence ${ }^{(2,10)}$. Epidemiological data on NP is difficult to obtain, as there are silent or non-symptomatic cases and, when symptomatic, they can be missed, as a result of bad medical judgment (misdiagnosis) or just because the patient doesn't search for health care advice. To surpass some of those issues, it was proposed to study the cadaver population present consecutively every early morning in the mortuary room (convenience sampling), during a relatively long period of time (to collect cases from almost an all year round). This approach has some limitations concerning the extrapolation of the results for the total population, as it is impossible to be sure that the studied sample is a good representative of the target population.

Given that, the results of the prevalence of the present study are higher than the two population-based studies from Sweden and Korea ${ }^{(1,3)}$. This is not surprising, as the present sample consisted mainly of old individuals, and it has been suggested that the prevalence of NP increases with age ${ }^{(1,11,12)}$. It was postulated that the longer inflammation in the respiratory tract persists, the greater is the risk of development of polyps; this thesis is supported by the fact that nasal polyposis is exceedingly rare in children (with the exception of cystic fibrosis) with a reported incidence of $0.1 \%{ }^{(12)}$. The present results are, in fact, in reasonably agreement with the estimated prevalence for older ages of the Skovde (Sweden) population-based study, in which the preva- lence of nasal polyps approached $5 \%$ at the ages of 60 years and up ${ }^{(1)}$.The lack of association between the clinical variables studied and the presence of NP adds to the need for more research in the field of pathophysiology of CRS with and without NP. Most worthy of notice is the absence of cases which have concomitant NP and Asthma. Although their inter-relationship is still poorly understood ${ }^{(13)}$, epidemiological studies ${ }^{(14)}$ and clinical practice impression, especially in more severe cases, frequently associate these entities. This finding raises the question whether asthma is underdiagnosed in this population. Moreover, the SARA study ${ }^{(15)}$ demonstrated that asthma in the elderly is frequently confused with chronic obstructive pulmonary disease or not diagnosed; it appears that older age and the greater degree of disability, together with a less typical clinical pattern, are the main causes of misdiagnosis. Also, the relative small number of cases with NP in the sample may contribute to these figures. Interesting is also the fact that none of the patients with NP had a record of previous ENT observation; this must be emphasized as one can presuppose that symptoms would have a low impact in quality of live. This also confirms the difficulties for an accurate estimate of the prevalence of NP based in questionnaires. This study provided the first epidemiological data on NP based in endoscopy in Portugal.

\section{Acknowlegdement}

Nothing to declare.

\section{Authorship contribution}

RC: Study design, data collection, statistical analysis, discussion, revision; RVT: Satistical analysis, discussion, revision; NL: data collection, revision; CPM: Study design, revision

\section{Conflicts of Interest}

The authors report no potential conflicts of interest relevant to this article.

\section{References}

1. Johansson L, Akerlund A, Holmberg K Melen I, Bende M. Prevalence of nasal polyps in adults: the Skovde population based study. Ann Otol Rhinol Laryngol 2003; 112 625-629.

2. Fokkens WJ, Lund VJ, Mullol J, et al. The European Position Paper on Rhinosinusitis and Nasal Polyps 2012. Rhinology 2012; Suppl. 23: 1-299

3. Min YG, Jung HW, Kim HS, Park SK, Yoo KY Prevalence and risk factors of chronic sinusitis in Korea: results of a nationwide survey. Eur ArchOtorhinolaryngol 1996; 253: 435439.

4. Larsen PL, Tos M. Origin of nasal polyps. The Laryngoscope 1991; 101: 305-312.

5. Larsen $\mathrm{PL}$, Tos M. Site of origin of nasal pol- yps. Transcranially removed nasoethmoidal blocks as a screening method for nasal polyps in autopsy material. Rhinology 1995; 33:185-188.

6. Larsen P. Anatomic site of origin of nasa polyps: endoscopic nasal and paranasal sinus surgery as a screening method for nasal polyps in autopsy material. Am J Rhinol 1996; 10: 211-216.

7. Larsen P, Tos M. Origin of Nasal Polyps: An Endoscopic Autopsy Study. Laryngoscope 2004; 114: 710-719.

8. Lund VJ. Diagnosis and treatment of nasa polyps. Br Med J 1995; 311: 1411-1414.

9. Hastan D, Fokkens WJ, Bachert C, et al Chronic rhinosinusitis in Europe - an underestimated disease. A GA2LEN study. Allergy 2011:66: 1216-1223.
10. Fokkens WJ, Lund V, Mullol J, et al. EPOS 2012: European position paper on rhinosinusitis and nasal polyps 2012. A summary for otorhinolaryngologists. Rhinology 2012; 50: 1-12.

11. Grigoreas C, Vourdas D, Petalas K, et al. Nasal polyps in patients with rhinitis and asthma. Allergy Asthma Proc. 2002; 23: 169-174.

12. Settipane GA. Epidemiology of nasal polyps. Allergy Asthma Proc. 1996; 17: 231-236.

13. Bousquet J, Van Cauwenberge P, Khaltaev $\mathrm{N}$, et al. Allergic rhinitis and its Impact on Asthma. J Allergy Clin Immunol. 2001; 108 (5 Suppl): S147-334.

14. Chung SD, Chen PY, Lin HC, Hung SH. Comorbidity profile of Chronic rhinosinusitis: a population-based study. Laryngoscope. 2014; 124: 1536-1541. 
15. Bellia V, Battaglia S, Catalano F, et al. Aging and disability affect misdiagnosis of COPD in eldery asthmatics: the SARA study. Chest 2003; 123: 1066-1072.
Rui Cerejeira

Department of Otolaryngology Tâmega e Sousa Hospital Center Penafiel

Portugal

Tel: 00351- 965487059

E-mail: r.cerejeira@netcabo.pt

\section{ADVERTISEMENT}

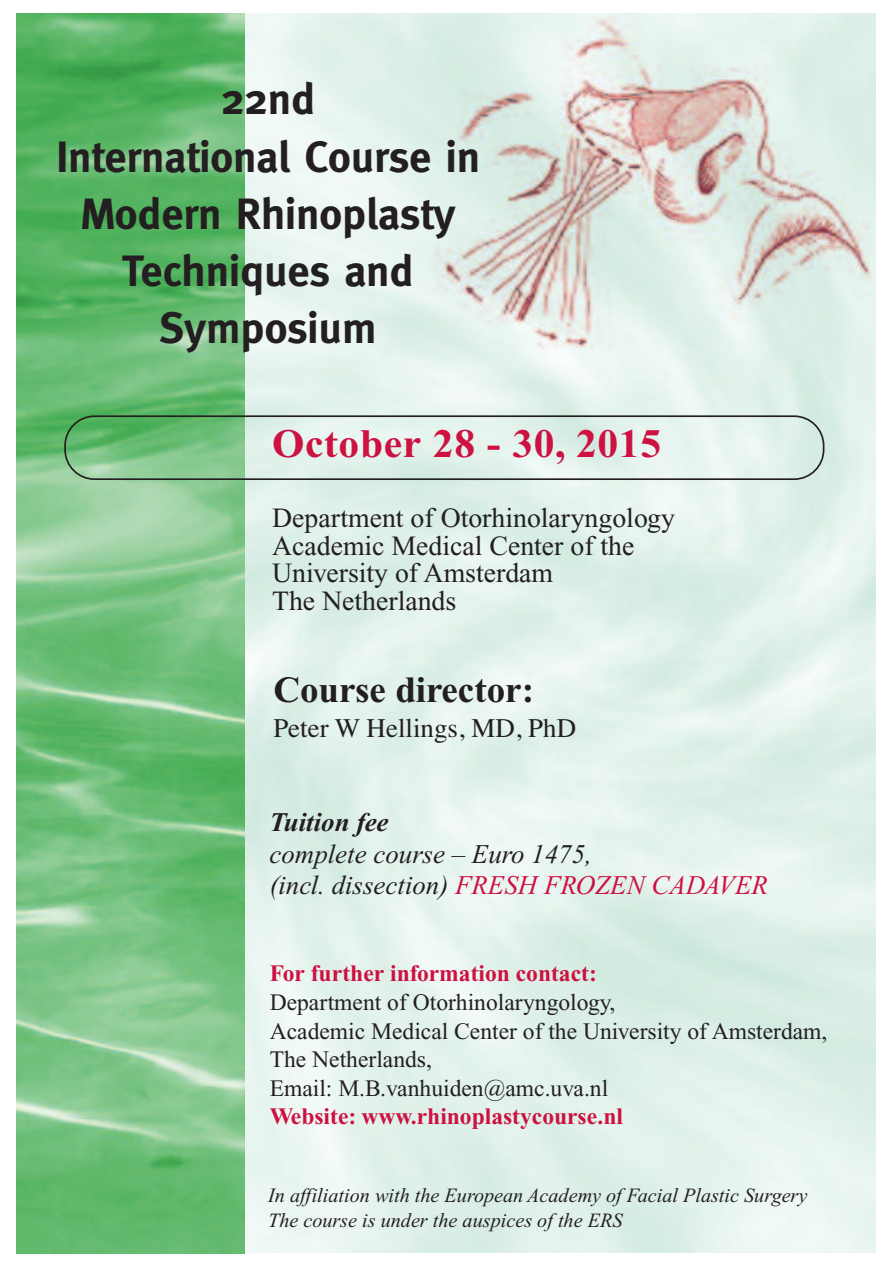

